\title{
Nestin, A New Marker, Expressed in Müller Cells Following Retinal Injury
}

\author{
Liping Xue, Peng Ding, Libo Xiao, Min Hu, Zhulin Hu
}

\begin{abstract}
Purpose: To investigate whether nestin would be a useful marker for retinal injury and also to ascertain a better understanding of the roles of Müller cells in the injured retina by the use of damaged rat retina. Methods: A total of 33 adult female Wistar rats were used in this study. Three were used as controls and the remaining as retinal injury modes (6 for hypoxia; 15 for experimental glaucoma and 9 for optic nerve transection). Double immunofluorescence labeling was carried out between nestin and glutamine synthetase (GS), and between glial fibrillary acidic protein (GFAP) and GS antisera in normal and pathological retinae. Results: The results showed that there were no nestin nor GFAP staining in mature Müller cells of the normal retina. A major finding was that nestin expression was induced in Müller cells subjected to hypoxia, glaucoma and optic nerve transection. Conclusions: These results suggest that nestin as well as GFAP (even more sensitive than GFAP) are useful and reliable biomarkers for retinal damage. The more intense expression of nestin, GFAP and GS in the end-feet of Müller cells suggest that they may help to maintain the retinal structural integrity and to enhance functional recovery in various retinal diseases.
\end{abstract}

RÉSUMÉ: La nestine, un nouveau marqueur exprimé dans les cellules de Müller suite à une lésion rétinienne. Objectif : Le but de l'étude était d'examiner si la nestine pourrait constituer un marqueur utile de lésion rétinienne et d'acquérir une meilleure compréhension des rôles des cellules de Müller dans la rétine qui a subi une lésion en utilisant la rétine de rat endommagée comme modèle. Méthodes : Trente-trois rats Wistar femelles ont été utilisés dans cette étude. Trois rats ont servi de contrôles et 30 ont servi de modèles de lésions rétiniennes (6 de lésion par hypoxie, 15 de glaucome expérimental et 9 de section du nerf optique). Un double marquage immunofluorescent a été réalisé dans la rétine normale et la rétine pathologique, d'une part pour la nestine et la glutamine synthétase (GS) et d'autre part pour la protéine acide fibrillaire gliale (GFAP) et l'antisérum GS. Résultats : Il n'y avait pas de nestine ou de GFAP dans les cellules de Müller matures de la rétine normale. L'expression de la nestine était induite dans les cellules de Müller soumises à l'hypoxie, au glaucome et à la section du nerf optique. Conclusions : Ces résultats suggèrent que la nestine, qui est plus sensible que la GFAP, de même que la GFAP sont des marqueurs utiles et fiables du dommage rétinien. L'expression plus intense de la nestine, de la GFAP et de la GS dans les pieds astrocytaires des cellules gliales de Müller suggère qu'il est possible qu'elles aident à maintenir l'intégrité de la structure rétinienne et à favoriser la guérison fonctionnelle dans plusieurs maladies rétiniennes.

Can. J. Neurol. Sci. 2010; 37: 643-649

The nestin gene, encoding the sixth class of intermediate filament, was originally cloned from an E15 rat central nervous system (CNS) cDNA library ${ }^{1}$. In the mammalian CNS, nestin has long been used as a cell distinguishing marker for radial glial cells and neural stem cells because of its characteristic expression in these cells ${ }^{1,2}$. However, results obtained from recent studies have proven that nestin can be expressed in other cells such as reactive astrocytes when the CNS is under trauma or stress ${ }^{3-5}$. With regards to the retina, nestin is not only expressed in immature Müller cells of the developing retina ${ }^{6-8}$, but it can be expressed in Müller cells following a toxic injury ${ }^{6-}$ ${ }^{9}$ or laser injury ${ }^{10}$ in the adult retina. The role of nestin expression in these cells remains elucidated. Glial fibrillary acidic protein (GFAP) is one of the third intermediate filaments expressed in mature astrocytes in the retina. Under normal circumstances, mature Müller cells do not express GFAP. However, in pathological conditions such as diabetic retinopathy ${ }^{11}$, glaucoma $^{12}$, ischemia $^{13}$ and light damage ${ }^{10,14}$, GFAP can be expressed in Müller cells. The induced expression of GFAP in Müller cells of pathological retinae only represents reactive gliosis. In the light of the above findings, we hypothesized that induced expression of nestin in Müller cells also represent a reactive gliosis to injury.

Hypoxia, experimental glaucoma and optic nerve transection (ONT) are well-established modes to study retinal damage. It has been proven in our and other previous studies ${ }^{8,12,15,16}$ that in these modes the retinae suffers from mild to severe damage with the loss of retinal ganglion cells. The main purpose of the current study is to use these three rat retinal damage modes to examine

From the State Key Laboratory of Ophthalmology (LXu), Zhongshan Ophthalmic Center, Sun Yat-Sen University, Guangzhou; Deparment of Ophthalmology (LXu, MH, LXi, ZH), Yunnan NO.2 Provincial People's Hospital; Department of Neurosurgery (PD), the First Affiliated Hospital of Kunming Medical College, Kunming, PR China. Received December 15, 2007. Final Revisions Submitted March 19, 2010. Correspondence to: Liping Xue, Department of Ophthalmology, Yunnan NO.2 Provincial People's Hospital, 176 Qingnian Rd, Kunming, PR China 650031. 
the relationship of nestin, GFAP and glutamine synthetase (GS) (which is an established marker for Müller cells) in damaged retinae and to investigate whether nestin would be a useful marker for retinal injury. This study may provide a better understanding of the roles of Müller cells in the injured retina.

\section{Methods And Materials}

A total of 33 adult female Wistar rats (weighing 180 240g; aged eight weeks) were used in this study. Food and water were provided ad libitum, and the animals were maintained on a 12 hour light-dark cycle. Three rats were used as controls, 6 rats for hypoxia, 15 rats for experimental glaucoma and 9 rats for ONT. The handling and care of all animals complied with the guiding principle of the Association for Research in Vision and Ophthalmology's Statement for the Use of Animals in Ophthalmic and Visual Research. All efforts were made to minimize the number of rats used and their suffering. The surgical procedures of the three retina injury modes are detailed below.

For hypoxia, treatment was done according to Kaur's method $^{17}$. Six rats were exposed to hypoxia by placing them in a hypoxic chamber (model 16M, Environmental Tectonics Corporation International, Southampton, PA, USA) at $9 \% \mathrm{O}_{2}$ for two hours. Of these, three rats were killed after 24 hours following exposure to normal conditions, the remaining three rats were immediately exposed to hyperoxia at $80 \% \mathrm{O}_{2}$ for two hours, and then killed 24 hours later ${ }^{17}$.

For experimentally induced glaucoma, 15 rats were anaesthetized by an intraperitoneal injection of $7 \%$ chloral hydrate $(350 \mathrm{mg} / \mathrm{kg})$. Limbus-draining veins were exposed and three of the four veins were cauterized using a small vessel cauterizer (Fine Science Tools, Canada). The detailed surgical procedures have been reported previously ${ }^{12,16}$. Only the right eye of each rat was used for this operation; the left one was sham operated and used as the control. The intraocular pressure (IOP) of both eyes was measured using a factory-calibrated Tono-Pen XL tonometer (Mentor, Norwell, USA) with $0.5 \%$ proparacaine topical anesthetic. Each IOP registered was an average of four consecutive measurements. The IOP measurements were recorded before and two hours after cauterization, and then one day, three days, one week and three weeks during the period before sacrifice. The IOP was considered as elevated only when the IOP of the operated right eye was at least $25 \%$ higher than that of the control left eye or the same eye before operation. Three rats were killed at each of the following time points: two hours, one day, three days, one week and three weeks postoperation for immunohistochemistry.

Nine rats were deeply anesthetized for ONT. According to Sarup's method ${ }^{18}$, skin incision along with superficial dissection was carried out avoiding the supraorbital vein. The optic nerve was exposed and the dura cut longitudinally. Complete optic nerve transection was performed $3 \mathrm{~mm}$ away from the globe. Care was taken to avoid injury to the ophthalmic artery and traction to the optic nerve. All optic nerve transections were performed at identical locations. The vascular circulation of each retina was assessed by the red reflex from the eye. Skin was sutured and erythromycin eye ointment was applied to the skin and eye. The left eye was sham operated and used as control. Three rats in each group were killed at one day, three days and one week post-operation.

For tissue section preparations, the deeply anesthetized rats were first perfused with Ringer's solution until the lungs and liver were cleared of blood and then perfused with $4 \%$ paraformal-dehyde in $0.1 \mathrm{M}$ phosphate buffer (PB; $\mathrm{pH} 7.4)$. After perfusion, the eyeballs were removed and immediately immersed in the same fixative for two to four hours before they were transferred into $0.1 \mathrm{M}$ PB containing $20 \%$ sucrose and kept overnight at $4^{\circ} \mathrm{C}$. Frozen sagittal sections of the eye were cut at $20 \mu \mathrm{m}$ thickness and mounted on chrome-alum-gelatin-coated slides. Sections were air-dried and stored at $-20^{\circ} \mathrm{C}$ until use.

For immunohistochemistry study, the mounted sections were washed for 20 minutes in $0.01 \mathrm{M}$ phosphate buffered saline containing $0.1 \%$ Triton X-100 (PBS-T; pH 7.4). Double immunofluorescence labeling was carried out between nestin

NOTE: To view figures in color, please go to our on-line issue. www.cjns.org.
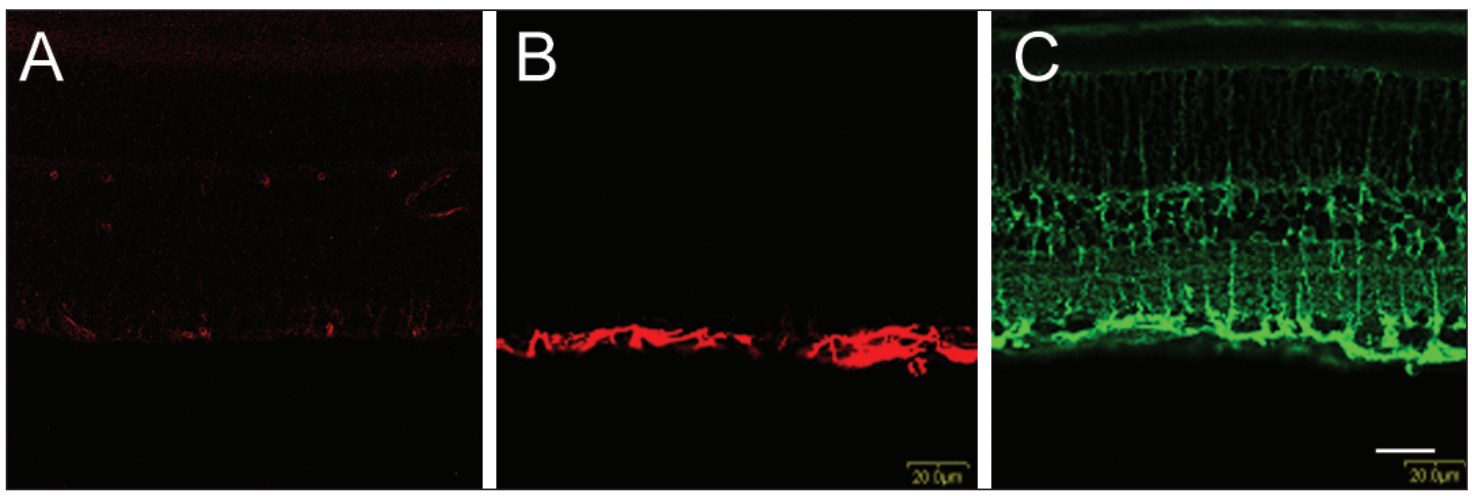

Figure 1: Immunostaining of nestin, GFAP and GS in normal mature rat retina. There were some weak nestin-staining identified as vascular profiles in the ganglion cell layer $(G C L)$ and no nestin staining in Müller cells (A). Antibody directed against GFAP specifically labeled astrocytes in the GCL and nerve fiber layer (NFL) but not Müller cells (B). GS immunoreactivity was localized mainly within the Müller cell soma and processes $(C)$. Scale bar=20 $\mathrm{\mu m}$ in $C$ (apply to A-C). 

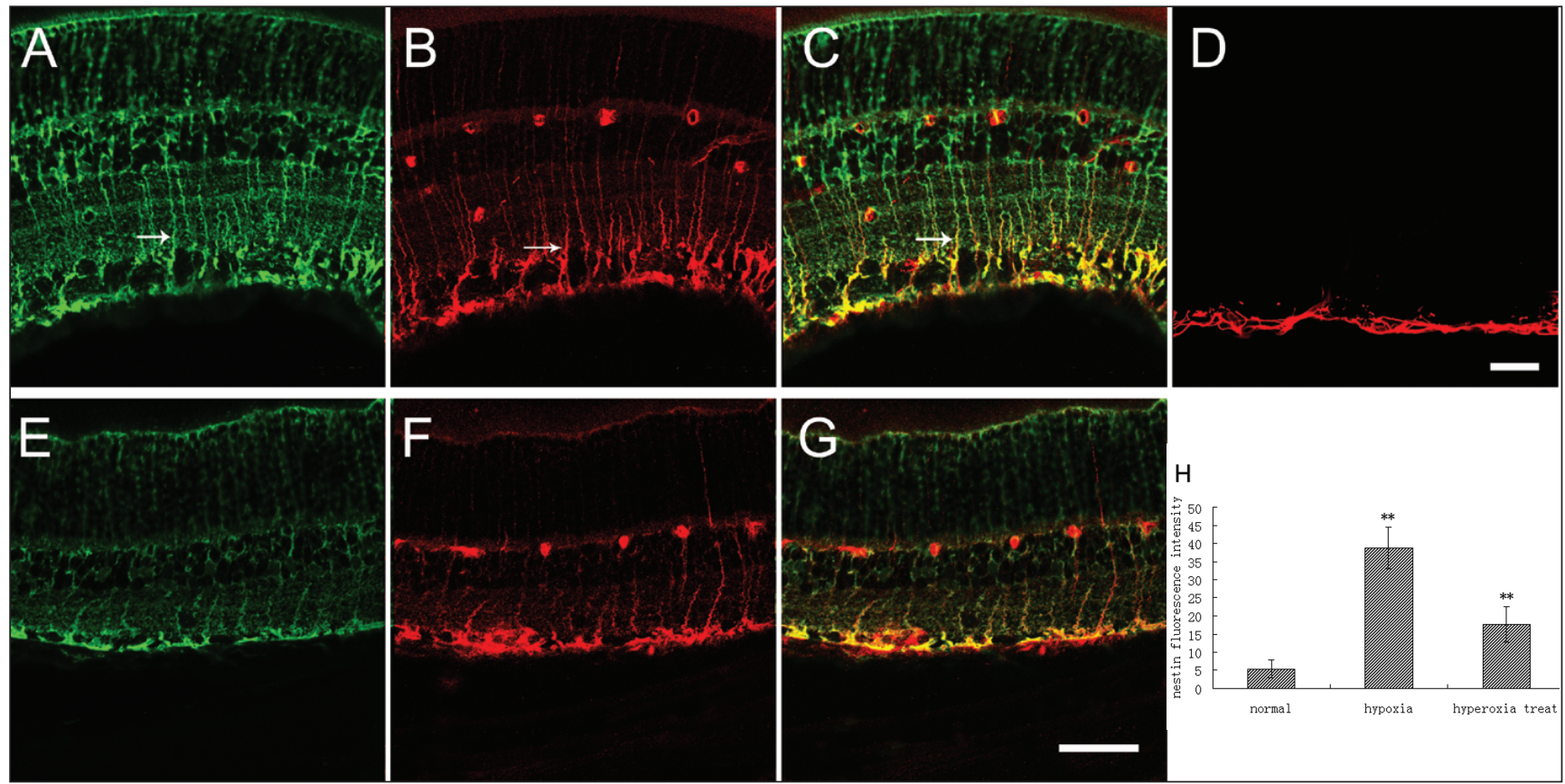

Figure 2: Immunostaining of nestin $(B, C), G F A P(D)$ and $G S(A, C)$ in retinae subjected to hypoxia $(A-D)$ and hyperoxia treating $(E-G)$. In retinae of rat exposed to hypoxia for 2 hours and killed 24 hours later, many nestin-positive cells and processes appeared to span through all retinal layers, including the ONL; some stained processes extended as far as to the photoreceptor layer (arrow in B). The increase in nestin immunoreactivity is most pronounced in the GCL where astrocyte processes and end-feet of the Müller glial cells were intertwined (arrow in B). All nestin-positive cells colabeled with GS staining (arrows in A,B,C). There is no detectable GFAP expression in Müller cells and it remains relatively stable in the $G C L$ compared to the normal retina $(D)$. In the retinae of rats subjected to hypoxia for 2 hours followed by immediate hyperoxia treatment for 2 hours and killed 24 hours later, nestin expression in the Müller cells is markedly decreased and its immunostaining is localized mainly in GCL $(E, F, G)$. The result of nestin fluorescence intensity analyzed by Image $J$ show that there were significant difference among normal, hypoxia and

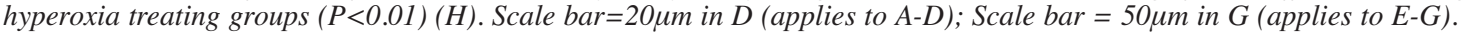

and GS, and between GFAP and GS antisera. The sections were incubated with a mixture of a mouse monoclonal antiserum against nestin (1:500 Chemicon, USA) or GFAP (1:1000; Sigma, USA) and a polyclonal rabbit antiserum against GS (1:1600; Chemicon, USA) in PBS -T overnight at room temperature. Nestin or GFAP was visualized using Cy3-conjugated goat antimouse IgG (1:200; sigma, USA) and for GS, Fluorescein isothiocynate-conjugated goat anti-rabbit $\operatorname{IgG}(1: 200$; sigma, USA) was used. The sections were then rinsed in two changes of PBS and covered with coverslips. Sections were examined in a confocal laser scanning microscope (Olympus FV 1000, Japan). Image $\mathrm{J}$ medical imaging software was used to analysis the fluorescence intensity.

\section{Results}

In the normal mature rat retina, nestin-positive staining was hardly detected except for some vascular profiles (Figure 1A). Glial fibrillary acidic protein-positive staining was mainly localized in the astrocytes in the ganglion cell layer (GCL) and nerve fiber layer (NFL) (Figure 1B) and absent in Müller cells. Glutamine synthetase immunoreactivity, as an established marker for Müller cells, was localized mainly within the Müller cell soma and processes (Figure 1C).

In rats subjected to hypoxia, it is clear that nestin was expressed in Müller cells (arrow in Figure 2B). Intense nestin

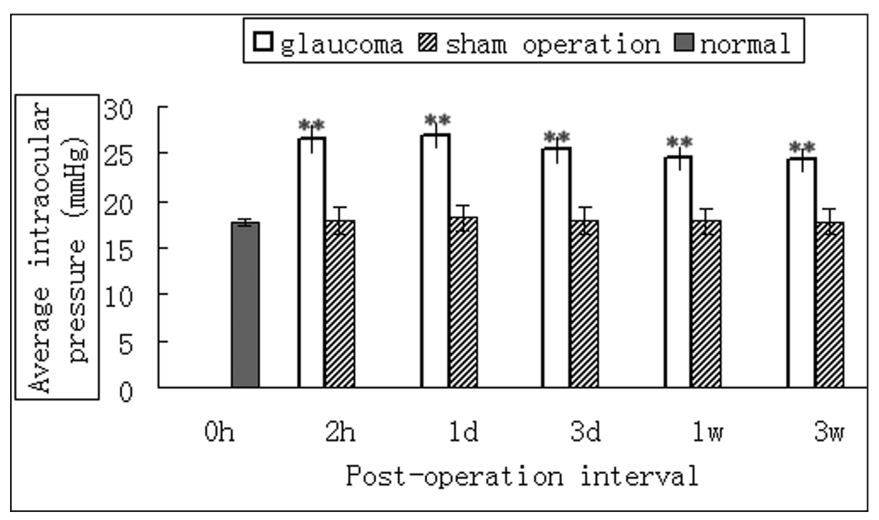

Figure 3: The average intraocular pressure of glaucomatous eyes. The intraocular pressure of the operated eye is obviously higher than that of the normal eye at each time point after operation $(P<0.01)$.

(red) expression was observed in Müller cells processes colabeled with GS (green) staining (arrows in Figures $2 \mathrm{~A}, \mathrm{~B}, \mathrm{C}$ ). Many nestin-staining tortuous processes appeared to span throughout all retinal layers and some processes extended as far as to the photoreceptor layer (arrow in Figure 2B). The somata of the Müller cells residing in the inner nuclear layer (INL) did not 
exhibit nestin staining. The induced nestin immunoreactivity was most pronounced in the GCL where the retinal ganglion cell somata were enmeshed in a network formed by the astrocytic processes and end-feet of Müller cells. Nestin colabeled with GS indicated that the nestin-positive cells were Müller cells. Glial fibrillary acidic protein immunoexpression was not detected in Müller cells and it remained relatively unchanged in the GCL compared to the normal retina (Figure 2D). In the retina of rats subjected to hypoxia for two hours followed by hyperoxia for the same duration and killed at 24 hours later, nestin expression in the GCL was markedly attenuated. Nestin colabeled with GS immunostaining was localized mainly in the GCL in a few fine processes of Müller cells (Figures 2E,F,G). The result of nestin fluorescence intensity analyzed by Image $\mathrm{J}$ show that there were significant difference among normal, hypoxia and hyperoxia treating groups $(\mathrm{P}<0.01)(\mathrm{H})$.

For experimental glaucoma model, the average IOP of normal and sham-operated control eyes was $17.60 \pm 0.43 \mathrm{mmHg}$. The mean IOP of the experimental eyes increased immediately after operation, and remained at a significantly elevated level throughout the entire length of the experiment $(\mathrm{P}<0.01)$ (Figure 3 ). The eye examination showed that cornea, lens and sclera appeared normal throughout the experiment.

In the glaucomatous retina, an increase in nestin staining superimposed with GS staining in the Müller cells was observed as early as two hours post-operation (Figure 4A). It was markedly enhanced at one day (date not shown) and three days (Figure 4B), being most intense at one week post-operation
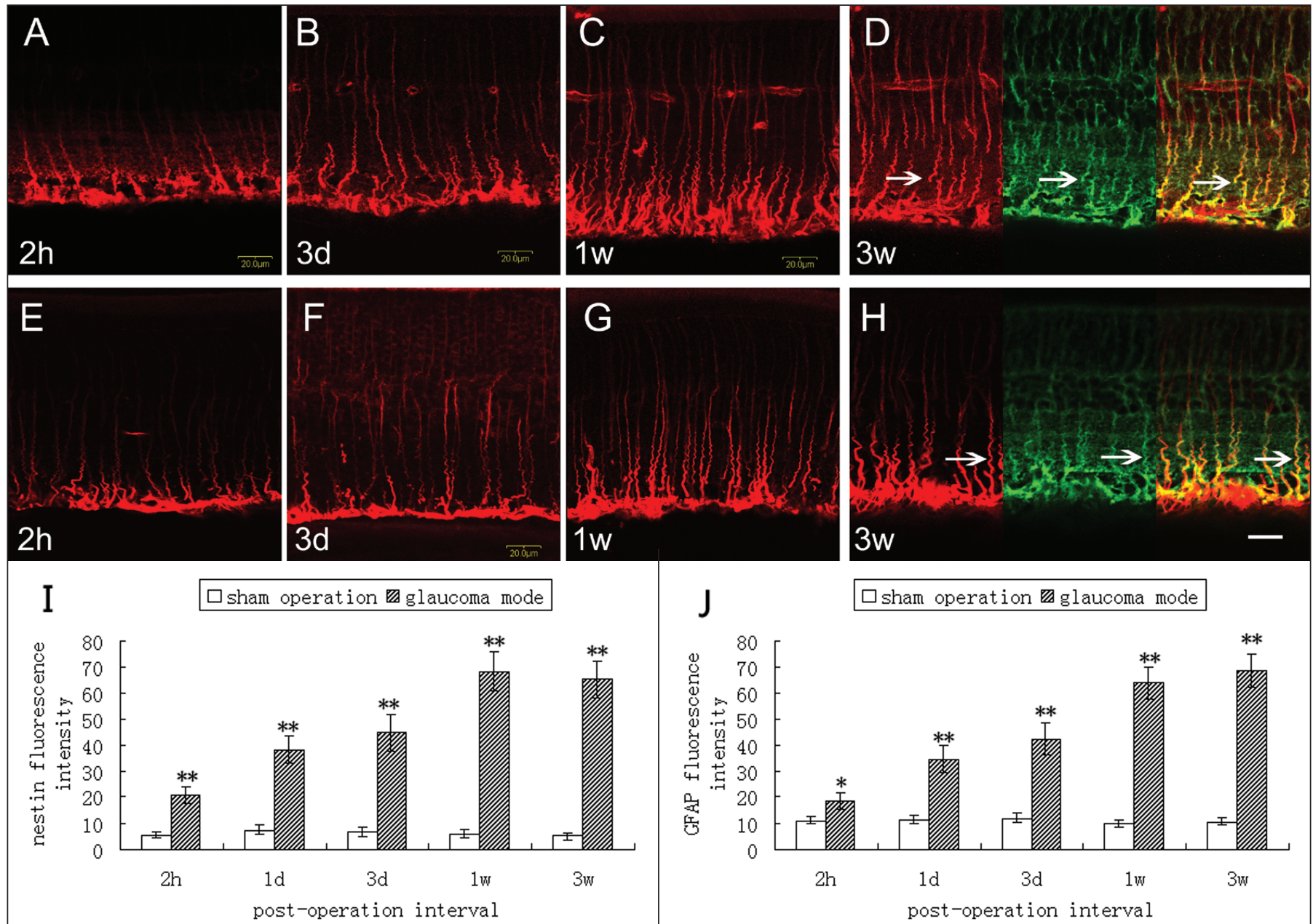

$\square$ sham operation glaucoma mode

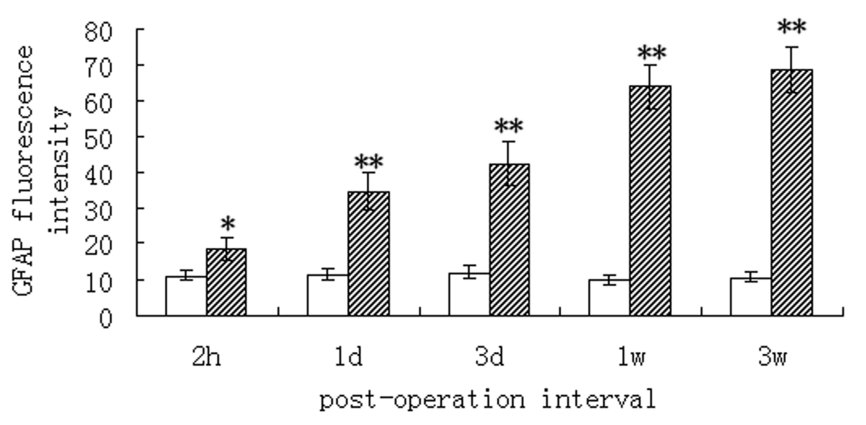

Figure 4: Expression of nestin and GFAP expression in Müller cells after elevated IOP. Induced expression of nestin was evident as early as 2 hours post-operation, notably intense at the end-feet of Müller cells (A). The expression of nestin is markedly enhance at 3 days (B), extremely intense at 1 week $(C)$ and remains strongly expressed at 3weeks $(D)$. The increase in nestin immunoreactivity colabeled with GS was most pronounced in the GCL where astrocytes processes and end-feet of the Müller cells were intertwined. The nestin-positive processes were hypertrophied in the inner retina but tapered off distally $(A, B, C, D)$. Analysis of nestin fluorescence intensity showed significant differences in each group $(P<0.01)(I)$. The expression of GFAP colabeled with GS in Müller cells presents as early as 2 hours post-operation (E), further increases at 3 days post-operation (F), appears to be most intensely stained at 1 week $(G)$ and remains elevated until 3 weeks after operation $(H)$.GS staining was translocated from the soma to the end-feet of Müller cells after operation (arrows in D,H, green). Analysis of GFAP fluorescence intensity showed significant differences in each group (P < 0.05 ) (J). Scale bar $=20 \mu \mathrm{m}$ in $H$ (applies to $\mathrm{A}-\mathrm{H}$ ) 


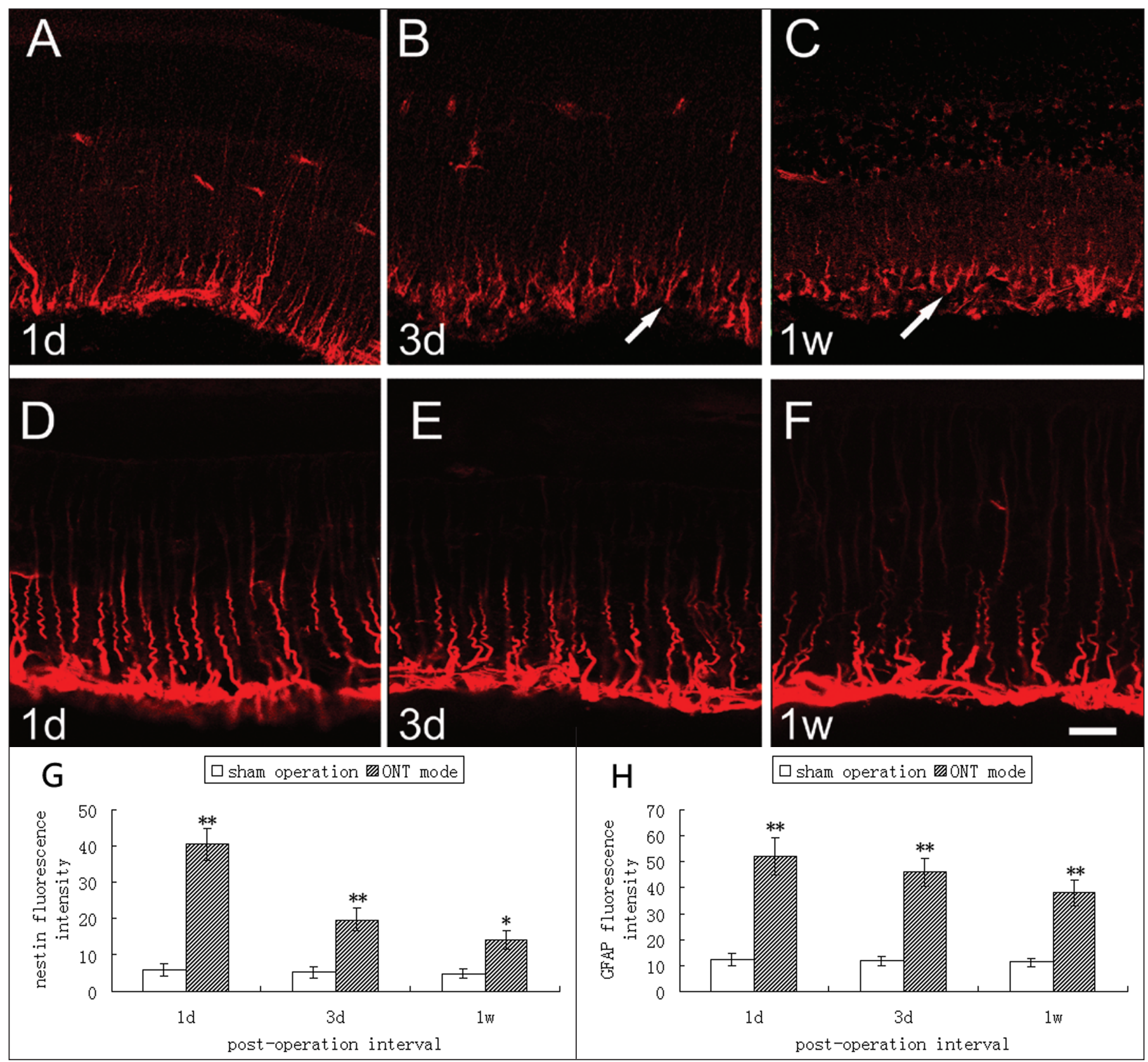

Figure 5: Expression of nestin $(A-C)$ and GFAP $(D-F)$ expression in Müller cells after ONT. Nestin staining as well as GFAP staining is marked enhanced in Müller cells at 1 day $(A, D)$ and 3 days $(B, E)$ after operation. With time duration, the expression of nestin and GFAP slightly decreased at 1 week post-operation $(C, F)$. The immunoreactivity of nestin and GFAP was greatly augmented in the inner retina where astrocytes and the end-feet of Müller cells encircle the retinal ganglion cells (arrows in B,C). Analysis of nestin and GFAP fluorescence intensity showed the tendency and the significant differences in each group $(P<0.05)(G, H)$. Scale bar $=20 \mu \mathrm{m}$ in $F$ (applies to A-F).

(Figure 4C) and remained strongly expressed until three weeks (Figure 4D). Some nestin-immunoreactive cells and processes could be observed to span throughout all retinal layers, including the outer nuclear layer and some processes extended even up to the photoreceptor layer. The nestin-positive processes were tortuous or serpentine-like and were grossly hypertrophied in the inner retina but tapered off distally (arrows in Figure 4D). Double immunolabeling with nestin and GS revealed that that these nestin-positive cells were Müller cells (arrows in Figure
4D). Analysis of nestin fluorescence intensity showed significant differences in each group $(\mathrm{P}<0.01)(\mathrm{I})$. In glaucomatous retinae, the pattern and level of GFAP induced expression were similar to nestin. It was clearly altered beginning two hours post-operation. The increase of GFAP expression was marked at one day (date not shown) and three days (Figure 4F) but was most dramatic at one week (Figure 4G) and three weeks (Figure 4H). Intensely stained GFAP processes colabeled with GS staining in parallel arrays extended across the entire thickness of the retina (arrows 
in Figure 4H). The somata of the Müller cells were unreactive for GFAP staining at all of the time points (Figure 4H). Double labeling with GFAP and GS has revealed that the GFAP-positive cells were Müller cells (arrows in Figure 4H). Analysis of GFAP fluorescence intensity showed significant differences in each group $(\mathrm{P}<0.05)(\mathrm{J})$. While GS immunoreactivity was observed to be more intense at or near the end-feet of Müller cells than the somata (arrows in Figure 4D, H green).

After ONT, increase in nestin expression was evident as early as one day and it was moderately increased in the GCL and inner plexiform layer. Nestin staining was localized in the radial processes extending into the INL (Figure 5A). Nestin staining was sustained at three days (Figure 5B) and slightly decreased at one week (Figure 5C) post-operation. Nestin-positive staining was especially intense at the end-feet of Müller cells anchored to the internal limiting membrane (arrows in Figures 5B,C). The remarkable increase in GFAP expression in the Müller cells was evident as early as 1d after ONT (Figure 5D). The enhanced GFAP staining was sustained in rats at three days (Figure 5E) and gently decreased at one week (Figure 5F) post-operation. The increase in GFAP or nestin immunoreactivity was most drastic in the vicinity of ganglion cells where the astrocytes and end-feet of the Müller cells were admixed. Analysis of nestin and GFAP fluorescence intensity showed the tendency and the significant differences in each group $(\mathrm{P}<0.05)(\mathrm{G}, \mathrm{H})$.

\section{Discussion}

The retina, an extension of the CNS into the eye, contains two major types of macroglial cells, namely Müller cells and astrocytes. Müller cells are specialized glia in the vertebrate retina which are not found elsewhere in the CNS. Their processes span the entire thickness of the retina and their endfeet encircle ganglion cells. The unique topographical distribution and configuration of Müller cells and astrocytes suggest that these glial cells provide specific structural support to retinal tissue especially in injuries ${ }^{19-21}$.

Corresponding well with previous results, our study also revealed that GFAP can be induced in Müller cells subjected to glaucoma and ONT. Glial fibrillary acidic protein-positive staining in Müller cells has been demonstrated to be a reliable indicator of acute and chronic neuroretinal pathology $y^{12}$.

Nestin is the sixth intermediate filament evidently expressed in stem cells or progenitor cells ${ }^{1,2}$. Recent studies have shown that nestin or transitin, a nestin-related intermediate filament, localized in differentiating and differentiated Müller cells ${ }^{6-8}$ can be induced in Müller cells following a toxic injury ${ }^{6-9}$ or laser injury ${ }^{10-14}$ in the adult retina. There are two notions about the nestin-positive cells in the retina. Some authors consider that nestin-positive cells represent a population of progenitor cells which can differentiate to form retinal scar tissue and provide the ability of regeneration throughout its life $\mathrm{e}^{6,7,9}$. Other authors consider that the induced expression of nestin, similar to GFAP, only represents reactive gliosis in the pathological retinae $e^{8,10,16}$. Though, the existence of nestin-positive progenitor cells in the mature mammalian retina has been proven, they are mainly located in the pigmented ciliary bodies, and the quantity is very ${ }^{10}{ }^{22}$. In consideration of the quantity, pattern and time of the induced expression of nestin coupled with GS in various diseased retinae, we support the latter notion.

\section{Conclusions}

Our results confirmed GFAP expression in injured retinae and revealed that nestin, similar to GFAP, can be induced in Müller cells after hypoxia, experimental glaucoma and ONT. Meanwhile, the induced expression of nestin in retinae subjected to hypoxia can be attenuated by treatment with hyperoxia. As with related studies of the CNS that show nestin expression in adult reactive astrocytes (following kainia acid lesions in the hippocampus) and in direct spinal cord trauma (without apparent reversion to the immature state after extended postoperative periods ${ }^{4,5}$ ), we conclude that nestin, similar to GFAP, is a useful and reliable marker for retinal injury. On one hand, the induction of nestin expression is rapid, drastic and can sustain for a long duration in injured retinae. On the other hand, the induction of nestin in injured retinae can be downregulated by therapy. In the light of our findings, as well as by others, we also conclude that the induced expression of nestin in Müller cells represents a general reaction of the diseased retinae but a specific phenomenon to pathognostic injury. However, there are some slight differences: only nestin and not GFAP expression was induced in Müller cells subjected to hypoxia. This novel finding may reveal a novel hypothesis that nestin may be a more sensitive biomarker than GFAP for retinal injury. Then, there needs to be caution in using nestin as a marker to distinguish neural stem cells in CNS.

In addition, a worthy feature was that the immunoreactivity of nestin and GFAP was greatly augmented in the inner retina and GS was translocated rapidly from the soma to the vicinity of ganglion cells. Nestin and GFAP are plastic cytoskeleton proteins whose expression may vary with the functional states of cells and GS plays an important role in the conversion of glutamate into glutamine which can help protect ganglion cells from dying ${ }^{23}$. In view of the close spatial relationship of Müller cells, specifically with the ganglion cells, the augmented expression of nestin, GFAP and GS in the end-feet of Müller cells suggests that these proteins are involved the pathological processes of neuronal death and may help to maintain the retinal structural integrity and enhance functional recovery of ganglion cells in various pathologic retinae.

\section{ACKNOWLEDGEMENTS}

Liping Xue and Peng Ding contributed equally to this work. The authors thank Professor Ling Eng Ang (Department of Anatomy, Yong Loo Lin School of Medicine, National University of Singapore) for his helpful suggestions. This work was funded by the National Science Foundation of Yun Nan province (No.2009C135).

\section{NOTE}

To view figures in color, please go to our on-line issue. www.cjns.org. 


\section{REFERENCES}

1. Lendahl U, Zimmerman LB, McKay RD. CNS stem cells express a new class of intermediate filament protein. Cell. 1990; 60(4): 585-95.

2. Kawaguchi A, Miyata T, Sawamoto K, Takashita N, Murayama A, Akamatsu W, et al. Nestin-EGFP transgenic mice: visualization of the self-renewal and multipotency of CNS stem cells. Mol Cell Neurosci. 2001; 17(2):259-73.

3. Brook GA, Perez-Bouza A, Noth J, Nacimiento W. Astrocytes reexpress nestin in deafferented target territories of the adult rat hippocampus. Neuroreport. 1999; 10(5):1007-11.

4. Clarke SR, Shetty AK, Bradley JL, Turner DA. Reactive astrocytes express the embryonic intermediate neurofilament nestin. Neuroreport. 1994; 5(15):1885-8.

5. Frisen J, Johansson CB, Torok C, Risling M, Lendahl U. Rapid, widespread, and longlasting induction of nestin contributes to the generation of glial scar tissue after CNS injury. J Cell Biol. 1995; 131(2):453-64.

6. Fischer AJ, Omar G. Transitin, a nestin-related intermediate filament, is expressed by neural progenitors and can be induced in Müller glia in the chicken retina. J Comp Neurol. 2005; 484 (1):1-14.

7. Walcott JC, Provis JM. Müller cells express the neuronal progenitor cell marker nestin in both differentiated and undifferentiated human foetal retina. Clin Exp Ophthalmol. 2003; 31(3):246-9.

8. Xue LP, Lu J, Cao Q, Kaur C, Ling EA. Nestin expression in Müller glial cells in postnatal rat retina and its upregulation following optic nerve transection. Neuroscience. 2006; 143(1):117-27.

9. Ooto S, Akagi T, Kageyama R, Akita J, Mandai M, Honda Y, et al. Potential for neural regeneration after neurotoxic injury in the adult mammalian retina. Proc Natl Acad Sci USA. 2004; 101 (37):13654-9.

10. Kohno H, Sakai T, Kitahara K. Induction of nestin, Ki-67, and cyclin D1 expression in Müller cells after laser injury in adult rat retina. Graefes Arch Clin Exp Ophthalmol. 2006; 244(1):90-5.

11. Zeng XX, Ng YK, Ling EA. Neuronal and microglial response in the retina of streptozotocin-induced diabetic rats. Vis Neurosci. 2000; 17(3):463-71.

12. Wang X, Tay SS, Ng YK. An immunohistochemical study of neuronal and glial cell reactions in retinae of rats with experimental glaucoma. Exp Brain Res. 2000; 132(4):476-84.
13. Zahir T, Klassen H, Young MJ. Effects of ciliary neurotrophic factor on differentiation of late retinal progenitor cells. Stem Cells. 2005; 23(3):424-32.

14. Grosche J, Hartig W, Reichenbach A. Expression of glial fibrillary acidic protein (GFAP), glutamine synthetase (GS), and Bcl-2 protooncogene protein by Müller (glial) cells in retinal light damage of rats. Neurosci Lett. 1995; 185(2):119-22.

15. Chen YN, Yamada H, Mao W, Matsuyama S, Aihara M, Araie M. Hypoxia-induced retinal ganglion cell death and the neuroprotective effects of beta-adrenergic antagonists. Brain Res. 2007; 1148:28-37.

16. Xue LP, Lu J, Cao Q, Hu S, Ding P, Ling EA. Müller glial cells express nestin coupled with glial fibrillary acidic protein in experimentally induced glaucoma in the rat retina. Neuroscience. 2006; 139(3):723-32.

17. Kaur C, Sivakumar V, Singh G, Singh J, Ling EA. Response of Purkinje neurons to hypobaric hypoxic exposure as shown by alteration in expression of glutamate receptors, nitric oxide synthases and calcium binding proteins. Neuroscience. 2005; 135(4):1217-29.

18. Sarup V, Patil K, Sharma SC. Ciliary neurotrophic factor and its receptors are differentially expressed in the optic nerve transected adult rat retina. Brain Res. 2004; 1013(2):152-8.

19. Bignami A, Dahl D. The radial glia of Müller in the rat retina and their response to injury. An immunofluorescence study with antibodies to the glial fibrillary acidic (GFA) protein. Exp Eye Res. 1979; 28(1):63-9.

20. Ekstrom P, Sanyal S, Narfstrom K, Chader GJ, Van Veen T. Accumulation of glial fibrillary acidic protein in Müller radial glia during retinal degeneration, Invest Ophthalmol Vis Sci. 1988; 29(9):1363-71.

21. Merrill JE. The role of microglial cells and astrocytes in pathology: introduction. Dev Neurosci 1994; 16:113.

22. Tropepe V, Coles BL, Chiasson BJ, Horsford DJ, Elia AJ, Mclnnes $\mathrm{RR}$, et al. Retinal stem cells in the adult mammalian eye. Science. 2000; 287(5460):2032-6.

23. Osborne NN, Ugarte M, Chao M, Chidlow G, Bae JH, Wood JP, et al. Neuroprotection in relation to retinal ischemia and relevance to glaucoma. Surv Ophthalmol. 1999; 43:S102-28. 